\title{
Ischemic heart disease mortality trends in Croatia between 1995 and 2011: a joinpoint regression analysis
}

\author{
Verica Kralj*, Mario Šekerija \\ Croatian National Institute of Public Health, Zagreb, Croatia
}

Aim: In the last few decades, mortality from ischemic heart disease has been decreasing in many countries. The aim of this study was to analyze trends in ischemic heart disease mortality rates in Croatia between 1995 and 2011.

Materials and methods: The data on deaths from ischemic heart diseases in Croatia were extracted from the WHO mortality database, and estimates of the Croatian population were derived from the Population Division of the Department of Economic and Social Affairs of the United Nations. Ischaemic heart diseases were defined as I20-I25 diagnoses in ICD-10. We used Joinpoint Regression analysis to describe mortality time trends, with up to 4 joinpoints and a Monte Carlo simulation to calculate $p$-values for a series of permutation tests. The joinpoint analysis was applied to the

\section{Received: $30^{\text {th }}$ Apr 2014}

*Address for correspondence: Hrvatski zavod za javno zdravstvo, Rockefellerova 7, HR-10000 Zagreb, Croatia.

Phone: +385-1-4863-271

E-mail: verica.kralj@hzjz.hr age-standardised rates (world population) and their standard errors, separately for each sex.

Results: There were 165,432 deaths due to ischemic heart disease in Croatia in this 17-year period (51.2\% females). The age-standardized ischemic heart disease mortality rates declined from 139.9/100,000 in men and 79.4/100,000 in women in 1995 to $118.9 / 100,000$ and $67.6 / 100,000$ in 2011, respectively. The trends showed a constant decrease, without any joinpoints in both men and women. In men, the best fitting model showed that in the period from 1995-2011 mortality rates significantly decreased (annual percent change (APC) of $-1.0 \% ; 95 \% \mathrm{Cl}-1.4$ to -0.6 ), while in women trends were also decreasing (APC of $-0.8 \% ; 95 \% \mathrm{Cl}-1.3$ to -0.3 ) throughout the entire study period.

Conclusion: Mortality rates for ischaemic heart disease showed a continuous decrease during this period, especially in men. However, it is still the leading cause of death, and it is important to monitor trends and focus on reduction of preventable risk factors.

KEYWORDS: ischemic heart disease, mortality rate, trends. CITATION: Cardiol Croat. 2014;9(5-6):161.

\section{Literature}

1. Kralj V. Cardiovascular diseases - magnitude of the problem and possibilities of prevention. Cardiol Croat. 2012;7(9-10):231-3.

2. Nichols M, Townsend N, Scarborough P, et al. European Cardiovascular Disease Statistics 2012. Brussels: European Heart Network, Sophia Antipolis: European Society of Cardiology, 2012.

3. Peeters A, Nusselder WJ, Stevenson C, Boyko EJ, Moon L, Tonkin A. Age-specific trends in cardiovascular mortality rates in the Netherlands between 1980 and 2009 . Eur J Epidemiol. 2011;26:369-73. 